\title{
RESEARCH ON SINTERIZED MATERIALS FROM METAL POWDER WITHOUT COBALT, FOR SPECIAL USES
}

\author{
Aurel Zapciu', Marian Vocurek ${ }^{2}$, Florin Izvoranu ${ }^{3}$, Iulian Sorin Munteanu ${ }^{4}$, \\ Liliana Laura Badita ${ }^{5}$, Valentin Gornoavă ${ }^{6}$ \\ 1,2,4, 5,6 National Institute of Research and Development in Mechatronics and Measurement Technique, Bucharest, \\ Romania, \\ ${ }^{3}$ Institute of Solid Mechanics of the Romanian Academy, Bucharest, Romania \\ E-mail: incdmtm@incdmtm.ro, imsar@imsar.bu.edu.ro
}

\begin{abstract}
It is estimated that in the coming years, the materials market will still dominate in them of tooling, cutting tools, mining inserts, molds and dies for cold and hot deformation, thermal screens, armor piercing cores, gamma screens, electrical contacts and high-voltage electrodes, accelerometer weights, radar antennas, thermocouples, etc., along with the emergence and development of new materials with high performance (ceramic materials, synthesis materials based on boron nitride synthetic diamonds, etc.).
\end{abstract}

Keywords: Sintered metals, metal powders without cobalt, sintered mixtures

\section{Introduction}

In order to obtain and process these materials, it is necessary to use specific methods of powder metallurgy which can very precisely control the physico-chemical properties of the final products.

Thereby, due to the rigor and precision of the components forming the pulverulent mixtures, materials that cannot be achieved by classical metallurgical processes with a high degree of repeatability can be obtained.

The composite materials obtained from powder metallurgy are in continuous development managing to capture the widest ranges of fields that represent the most dynamic development of the use of metallic materials.

The economic efficiency of powder metallurgy is manifested on several levels, involving, in addition to the direct or indirect savings of metal or energy, the following aspects:

- improving the performance and functional parameters of the machines on which sintered parts are mounted;

- increasing the productivity of some technological processes using powdered metallurgy products;

- refurbishing massive and complex products;

- recovery of waste in the form of metallic powders (iron oxides, technical copper waste);

- upper metal valorization.

The technical advantages of powder metallurgy are:

- allows the completion and development of the nomenclature of products manufactured in the various branches of industry;

- offers, in some cases, the only rational solution, viable and advantageous to the elaboration of materials and products with special properties, which cannot be obtained by classical technological processes;

- $\quad$ allows the production of high quality parts with a minimum metal content and high productivity;

- is an important step in the study of the structure of metallic materials;

- it facilitates the production of a series of metals and alloys with high melting temperature.

\section{Systemic Study on the Technology of Manufacturing Parts of Powder Based on Tungsten}

Tungsten, the metal from the transition metals group, is found in nature in the form of ores. Very tough, with a melting point of $3410{ }^{\circ} \mathrm{C}$, has a density of $19.2 \mathrm{~g} / \mathrm{cm} 3$. Tungsten carbide can be processed with the best results through powder metallurgy.

Research on sintered materials from cobalt-free metal powders with special uses:

In general, more than $80 \%$ of the production of materials made by powder metallurgy is represented by tungsten carbides for use in the machine industry for metal cutting, mining and oil drilling industry, special destinations, etc. 
Tungsten powder blends are an important niche lately and it's addressed to electronics industry, specialty production, etc., with features such as thermal screens, armor piercing cores, gamma ray screens, oven screens, and thermocouples.

\subsection{Aggregation with powder}

Is a process of dimensional processing that has undergone wide development in all branches of industry. As opposed to classical metallurgy (based on melting and casting), this process involves the production and use of metallic powders, as such, or in the form of sintered products, characterized essentially by the fact that:

- is based on welding phenomena of metallic particles under influence of pressure and heat;

- avoid the melting and casting of metals or their alloys;

- apply a part of the classical technology for the development of the actual ceramic products (porcelain, refractory materials, etc.);

- allows products with less complex configuration to be obtained directly to the geometric shape and final dimensions, without further processing.

The process of powder aggregation is very interesting. This is based on metal powders (or metallic or even metalloid combinations) that will be intimately mixed in the required proportions corresponding to the chemical composition of the alloy that we want to obtain. Once these two processes have been completed, the following step is taken: the obtained mixture is pressed into the desired form in the metal molds and the powdered tablets thus obtained are subjected to a suitable heat treatment to obtain the relatively compact bodies with the desired physico-mechanical properties.

\subsection{Dosage of powders}

The mixture of metallic powders which constitute the raw material for the production of the "pill", used in the special production, has a very low flow rate, therefore, a granulation process is used.

Table 1 shows the range of mixtures of tungstenbased metallic powders, with reduced iron and nickel powders, as well as their physico-mechanical characteristics.

Table 1 - Characteristics of the mixture of tungsten, nickel and iron powders

\begin{tabular}{|c|c|c|c|c|c|c|}
\hline $\begin{array}{l}\text { Sorts - name / physico- } \\
\text { mechanical properties }\end{array}$ & HA 190 & HA 193 & HA 195 & HE 395 & HE 397 & HM 490 \\
\hline Nominal composition & $\begin{array}{l}90 \% \mathrm{~W} \\
6 \% \mathrm{Ni} \\
4 \% \mathrm{Cu}\end{array}$ & $\begin{array}{l}93 \% \mathrm{~W} \\
4,9 \% \mathrm{Ni} \\
2,1 \% \mathrm{Cu}\end{array}$ & $\begin{array}{l}95 \% \mathrm{~W} \\
4 \% \mathrm{Ni} \\
1 \% \mathrm{Cu}\end{array}$ & $\begin{array}{l}95 \% \mathrm{~W} \\
3,5 \% \mathrm{Ni} \\
1,5 \% \mathrm{Fe}\end{array}$ & $\begin{array}{l}97 \% \mathrm{~W} \\
2,1 \% \mathrm{Ni} \\
0,9 \% \mathrm{Fe}\end{array}$ & $\begin{array}{l}90 \% \mathrm{~W} \\
4 \% \mathrm{Ni} \\
2 \% \mathrm{Fe} \\
4 \% \mathrm{Mo} \\
\end{array}$ \\
\hline Density & $\begin{array}{l}16,9 \\
\mathrm{~g} / \mathrm{cm}^{3}\end{array}$ & $\begin{array}{l}17,7 \\
\mathrm{~g} / \mathrm{cm} 3\end{array}$ & $\begin{array}{l}18 \\
\mathrm{~g} / \mathrm{cm}^{3}\end{array}$ & $18,1 \mathrm{~g} / \mathrm{cm}^{3}$ & $\begin{array}{l}18,5 \\
\mathrm{~g} / \mathrm{cm}^{3}\end{array}$ & $\begin{array}{l}17,3 \\
\mathrm{~g} / \mathrm{cm}^{3}\end{array}$ \\
\hline $\begin{array}{l}\text { Flowing point } \\
\text { (Conventional Flow Limit } \\
0.2 \% \text { ) }\end{array}$ & $\begin{array}{l}550 \\
\mathrm{MPa} \\
80 \mathrm{ksi}\end{array}$ & $\begin{array}{l}650 \mathrm{MPa} \\
94 \mathrm{ksi}\end{array}$ & $\begin{array}{l}695 \mathrm{MPa} \\
100 \mathrm{ksi}\end{array}$ & $\begin{array}{l}570 \mathrm{MPa} \\
83 \mathrm{ksi}\end{array}$ & $\begin{array}{l}565 \mathrm{MPa} \\
82 \mathrm{ksi}\end{array}$ & $\begin{array}{l}680 \mathrm{MPa} \\
99 \mathrm{ksi}\end{array}$ \\
\hline $\begin{array}{l}\text { Maximum Tensile } \\
\text { Strength (UTS) }\end{array}$ & $\begin{array}{l}790 \\
\mathrm{MPa} \\
115 \mathrm{ksi}\end{array}$ & $\begin{array}{l}820 \mathrm{MPa} \\
119 \mathrm{ksi}\end{array}$ & $\begin{array}{l}800 \mathrm{MPa} \\
116 \mathrm{ksi}\end{array}$ & $\begin{array}{l}900 \mathrm{MPa} \\
130 \mathrm{ksi}\end{array}$ & $\begin{array}{l}800 \mathrm{MPa} \\
115 \mathrm{ksi}\end{array}$ & $\begin{array}{l}880 \mathrm{MPa} \\
128 \mathrm{ksi}\end{array}$ \\
\hline Elongation & $\begin{array}{l}8 \% \\
25 \mathrm{~mm}\end{array}$ & $\begin{array}{l}8 \% \\
25 \mathrm{~mm}\end{array}$ & $\begin{array}{l}5 \% \\
25 \mathrm{~mm}\end{array}$ & $\begin{array}{l}15 \% \\
25 \mathrm{~mm}\end{array}$ & $\begin{array}{l}6 \% \\
25 \mathrm{~mm}\end{array}$ & $\begin{array}{l}13 \% \\
25 \mathrm{~mm}\end{array}$ \\
\hline Hardness & $24 \mathrm{HRC}$ & $24 \mathrm{HRC}$ & $24 \mathrm{HRC}$ & 26 HRC & $27 \mathrm{HRC}$ & $27 \mathrm{HRC}$ \\
\hline
\end{tabular}

Since these powders are in the $2 \div 4 \mu \mathrm{m}$ dimensional range, in order to avoid jamming the punch during the pressing of the powder in the die (the gap between the die and the punch may be greater than or equal to the particle size granules), the granulation procedure is used.

Granulation is executed using less automated technologies due to the low quantities of required products.

Spheroidization technologies, as in the case of tungsten carbide powders, cannot be used because the equipment is contaminated with carbon that would compromise the final product.

Granulation is carried out in several stages: 
a) Mixing the tungsten, iron and nickel powder with distilled water in a proportion of $15 \%$ of the powder weight and polyethylene glycol (PEG 400) in proportion of $0.8 \%$ of the powder weight.

PEG 400 is a low molecular weight poly-ethylene glycol type. It is a clear, colorless, viscous liquid. Because of its low toxicity, PEG 400 is widely used and in a variety of pharmaceutical products. Some of the physico-chemical characteristics of PEG 400 are:

- Density: $1.13 \mathrm{~g} / \mathrm{cm}^{3}$

- Chemical formula $\mathrm{C} 2 \mathrm{nH} 4 \mathrm{n}+2 \mathrm{On}+1, \mathrm{n}=8.2 \div$ 9.1

- Melting point: $4 \div 8{ }^{\circ} \mathrm{C}\left(39 \div 46^{\circ} \mathrm{F} ; 277 \div 281 \mathrm{~K}\right)$

- Viscosity $90.0 \mathrm{cSt}$ at $25^{\circ} \mathrm{C}, 7.3 \mathrm{cSt}$ at $99^{\circ} \mathrm{C}$

- Molar mass: 380-420 g/ mol

drying in the oven at $1300^{\circ} \mathrm{C}$ for 1 hour

mechanized sieve of 0,5 and $0,25 \mathrm{~mm}$

Figure 1 shows a microscope obtained image (x20) of granulated HE 395 powder (Table 2.1). The globular form of granules with dimensions of $0.01 \ldots$ $0.5 \mathrm{~mm}$ is observed.

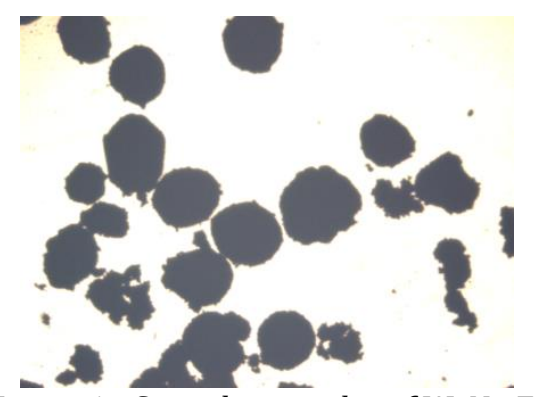

Figure 1: Granular powder of $\mathrm{W}, \mathrm{Ni}, \mathrm{Fe}$

The difficulty of the granulation process lies in the fact that the mixture consists of three kinds of powders with very different densities and a homogeneity of the mixture must be ensured.

- Density W ....... 19,25 g / $\mathrm{cm}^{3}$

- Density Ni .......... $8.9 \mathrm{~g} / \mathrm{cm}^{3}$

- Density Fe ......... $7.86 \mathrm{~g} / \mathrm{cm}^{3}$

The granular powder obtained has substantially improved flow properties, but not good enough to attempt an automatic dosage.

In Figures 2, 3 there are presented the stages of the granulation of the metallic powders, the assortment chosen for the execution of the pill types is HE 395.

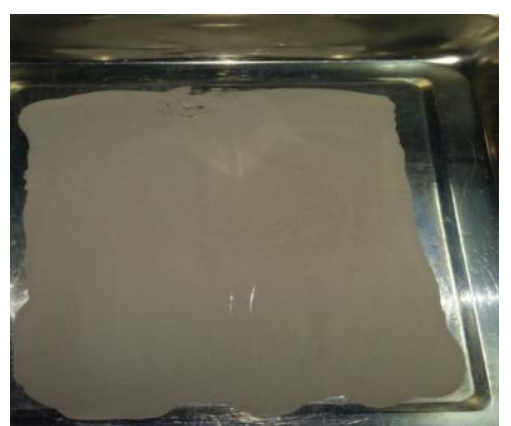

Figure 2: Powder mixed with water and PEG prepared for the drying process in the oven

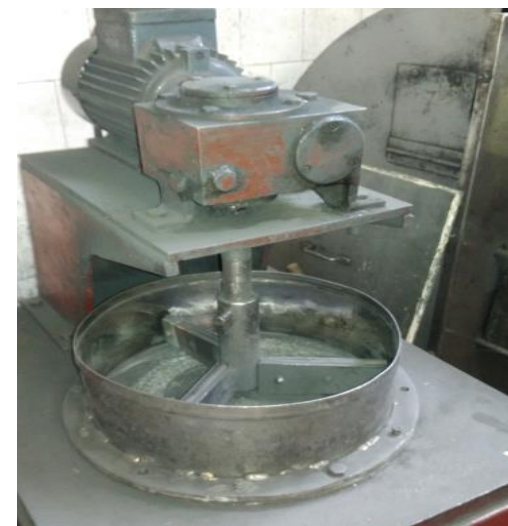

Figure 3: Saturation of the granular powder into the granulometer

After sieving, the granulated powder is ready for dosing. The dosage is performed by manual weighing with a Mettler LJ16 thermo balance, with an accuracy of $0.001 \mathrm{~g}$.

As can be seen from the figure. 4 the amount of powder used for pressing is $12,140 \mathrm{~g}$.

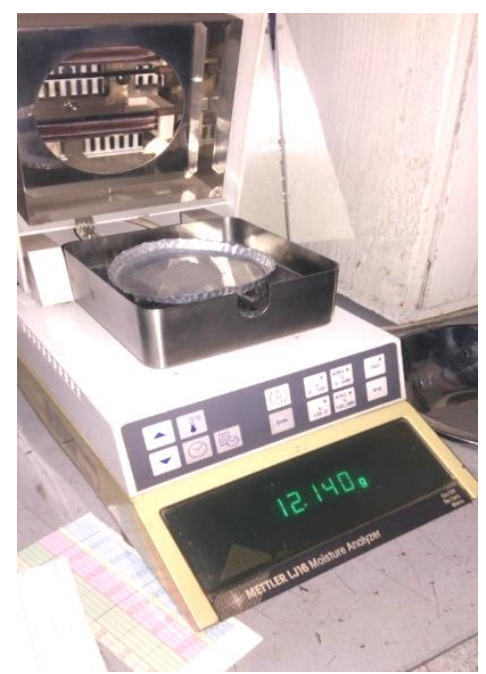

Figure 4: Mettler LJ16 thermobalance weighing dosing

\subsection{Powder pressing}

The reference part, referred as "Pill", is accomplished by bilateral pressing into the die on the Meyer hydraulic press of $15 \mathrm{tf}$ (Figure $5 \mathrm{a}, \mathrm{b}$ ).

Compaction will be accomplished in a mold made of OSC or C120 with hardness greater than 56 HRC that holds 50,000-10,000 press cycles (which provide products in initial parameters). In the event of a larger need for products, the pressing dies will be made of CMS (Sintered Metal Carbide) with harnesses greater than 1000 HV30. Regardless of the constructive solution chosen as a material, the surface quality must be particularly well achievable only by bonding with conventional abrasives (for steel) and diamond paste for CMS. The pressing of the raw material from the powder, the spheronization is performed on automatic presses in 
specially constructed molds, the pressing being bilateral and the dosage being volumetric; in case of small series, pressing is done on the presses, the dosing being manual.

The cold (and hot) pressing of metallic powders has the purpose and effect of compacting them and giving them certain shapes as close as possible to the final shapes of the pieces.

The degree of compaction of powders is directly influenced by the following factors:

- applied pressure

- how the pressure is applied

- the geometric shape of the piece

- During the pressing process, the following phenomena occur:

- destruction of voids and bridges in the mass of powder (intergranular spaces).

- approaching the powder particles (granules) of each other and shaping the shapes so that spaces between them become smaller or eliminated.

- there is a sliding of particles between the particles and a densification of the volume occupied by them.

- destruction of particle agglomerates and circular or lacy forms (toothed).

- increasing the pressure (1.5-3.0 t / cm2) further leads to the plastic deformation of the particles and the overlapping of the surfaces of the particles on top of each other, with the cold welding phenomenon (soldering).

- due to the adiabatic effect, a local increase in the temperature of the particles occurs at suddenly applied pressures, which can cause a new metal atomization in the configuration or even a hot welding of the particles. The compaction and densification degree of the pressed blank has a great influence on the geometric shape of the piece.

Also, the shapes with smaller or larger diameter, will have different degrees of compaction and will require different pressures for the same mass of material.

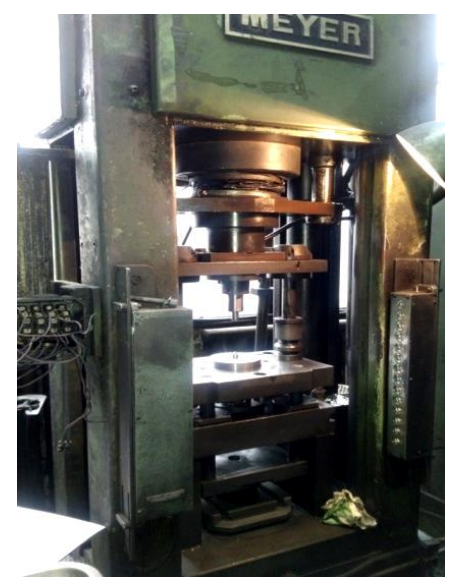

Figure 5 (a): 15 Mef Hydraulic Meyer Press equipped with adapter and press die

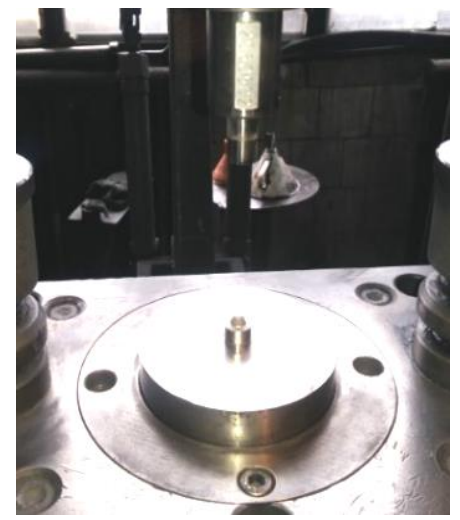

Figure 5 (b): CMS molding molded final product

For an better pressing it is necessary to maintain press forces applied for a relatively short time (up to 30 seconds) which allows both the equalizing of the internal stresses of the part and the complete discharge of the air included during the dosing.

\subsection{Sintering}

Sintering is a process of powder metallurgy that allows products with a less complex configuration to be obtained directly to the geometric shape and final dimensions without further processing. (Figure 6).

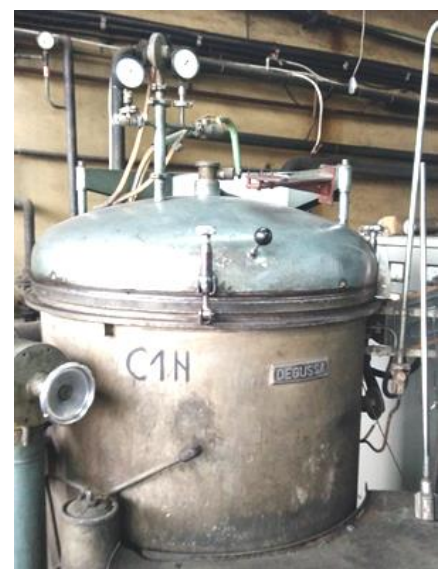

Figure 6: Degussa sintering furnace VSI 35/70

This treatment is complex, has several stages (presinterization, sintering, cooling) and can be done in several ways:

- on stationary furnaces (performs only certain stages of heat treatment)

- on "integrated" ovens (performs the complete heat treatment cycle);

- on propelled furnaces (the batch is located in the graphite nacelles and progressively progresses the furnace heating zones to the prescribed cycle).

The pieces sit in the graphite nails on a layer of corundum for insulation, thus removing the danger of carbon infestation and the formation of tungsten carbide (fig.7). 
Above the pieces is placed a layer of corundum until they are covered (fig. 8).

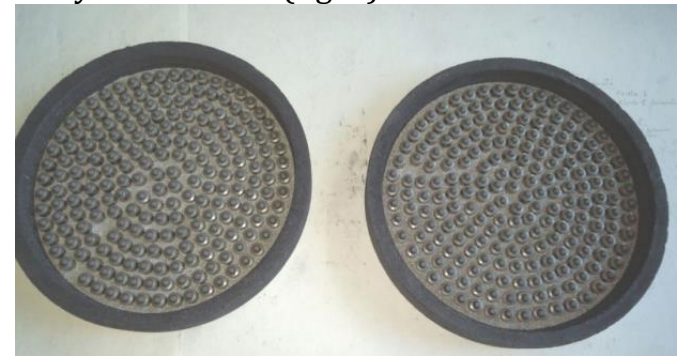

Figure 7: Parts placed in a graphite nacelle on a corundum

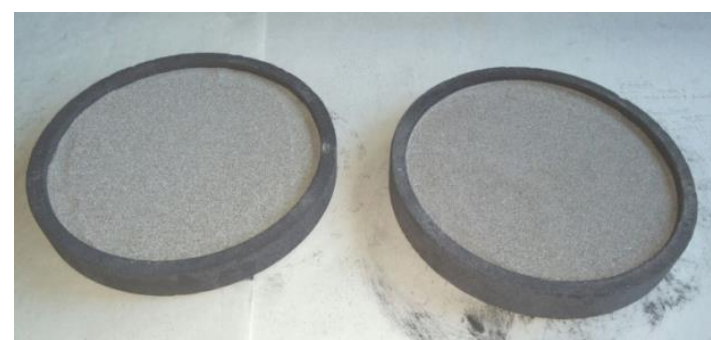

Figure 8: Pieces covered with corundum in the nacelle

Sintering the most important technological operation in the flow of sintered metal parts is a thermal treatment that leads to the formation of bonds between the particles of tungsten dust and the particles of nickel and iron powder in order to obtain superior product characteristics.

The new product is the tablet, in which the particles that formed it originally sintered by creating stable bonds.

All processes occurring during the liquid phase sintering of the $\mathrm{W}$ metallic powder are inherently related to the superficial energy, which makes it the main driving force of the densification

This densification acting during liquid phase sintering is assumed to have a three-stage sequential deployment: the first stage, characterized by high velocity densities occurring at the onset of the liquid phase, the second stage due to reaching the eutectic temperature, characterized by - a continuous change of the structure in the sense of its establishment by completing the contacts between the solid particles and the third stage, characterized by the insignificant densification velocity, in which the mass transfer is realized by the solid state diffusion.

Through this process, the pores can come out of the tablet, on the surface, if their size is smaller than the average clearance between the tungsten grains. Through this process, the pores can come out of the tablet, on the surface, if their size is smaller than the average clearance between the tungsten grains.

Such porosity can be prevented by choosing a working atmosphere and a heating gradient so that adequate degassing can be achieved.

Pores due to soluble gases are encountered in case of prolonged maintenance at the sintering temperature.

\section{Characterization of Mixtures of Tungsten-Based Powders}

The issues addressed relate to the production of sintered materials using powder metallurgy techniques / technologies and control systems.

By identifying the main parameters, specific (well defined) mixtures / recipes can be made, with precise destinations in the activities to be used:

- wear products;

- products with special destination.

As the main priorities imposed by the pulverulent mixtures it is necessary to achieve a rigorous control of the mixtures and their main influence parameters.

The particle-specific investigation system (Figure 7) was the subject of a project developed by INCDMTM and consists of the following main modules:

the investigative module allowing the mass-specific determinations of metallic powders to be carried out, namely:

- Determination of apparent density

- Determination of flow rate

- Moisture determination

- Determining the density of the blank

- Mass determinations are carried out using a 0,001 g precision thermo balance.

- The automation module that allows neutral atmosphere to be used to determine apparent density and flow rate.

- Data acquisition and monitoring module

Technical Characteristics of the Metal Powder Investigation System (Figure 7):

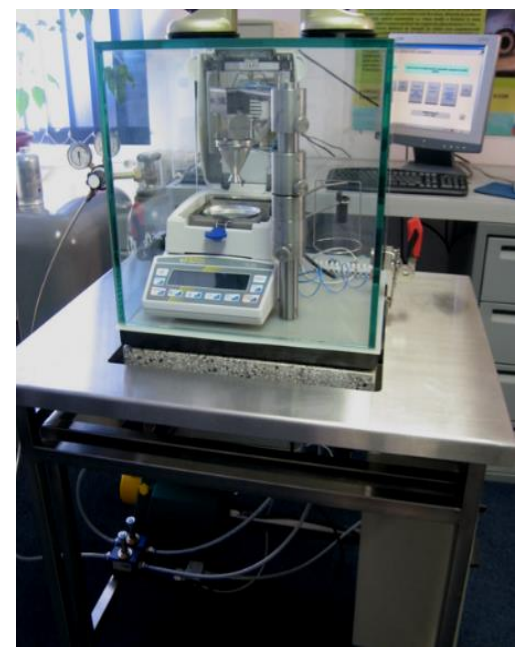

Figure 7: The Metal Powder Investigation System

1. Maximum sample weight $120 \mathrm{~g}$

2. Precision of weighing $0,001 \mathrm{~g}$

3. Drying temperature max. $250^{\circ} \mathrm{C}$

4. Vacuum achieved 0.6 bar

5. Absolute argon pressure 0.95 bar

6. RS232 serial interface

7. Power supply $220 \mathrm{~V}-50 \mathrm{~Hz}$ 
The powder mixture characteristics of tungsten, nickel and iron were presented in Table 1.

Tabel 2 - Contractions of five pressed and sintered

parts

\begin{tabular}{|c|c|c|c|c|c|c|}
\hline & \multicolumn{3}{|c|}{ Diameter $\varphi, \mathrm{mm}$} & \multicolumn{3}{|c|}{ Height $\mathrm{H}, \mathrm{mm}$} \\
\hline & \multicolumn{2}{|c|}{ Condition } & \multirow{2}{*}{$\begin{array}{l}\text { Contraction } \\
\%\end{array}$} & \multicolumn{2}{|c|}{ Condition } & \multirow{2}{*}{\begin{tabular}{|l}
$\begin{array}{l}\text { Contraction } \\
\%\end{array}$ \\
\end{tabular}} \\
\hline & Pressed & Sintered & & Pressed & Sintered & \\
\hline $\begin{array}{l}\text { Tungsten pill } \\
\text { nx } 1\end{array}$ & 12.28 & 10.97 & 10,66 & 12.50 & 10.92 & 12,06 \\
\hline $\begin{array}{l}\text { Tungsten pill } \\
\text { 도 } 2\end{array}$ & 12.29 & 10.97 & 10,74 & 12.51 & 10.94 & 12,55 \\
\hline $\begin{array}{l}\text { Tungsten pill } \\
\text { ne } 3\end{array}$ & 12.28 & 10.97 & 10,66 & 12.51 & 10.93 & 12,63 \\
\hline $\begin{array}{l}\text { Tungsten pill } \\
\text { ns } 4\end{array}$ & 12.29 & 10.98 & 10,65 & 12.50 & 10.92 & 12,06 \\
\hline $\begin{array}{l}\text { Tungsten pill } \\
\text { n. } 5\end{array}$ & 12.29 & 10.97 & 10,74 & 12.51 & 10.93 & 12,63 \\
\hline
\end{tabular}

\section{Physico-Mechanical Characterization} of Parts Made of Powder-Based Tungsten with the Addition of a Given Amount of Iron and Nickel.

Dimensional determination was performed using a workshop micrometer, range $0-25 \mathrm{~mm}$, measuring accuracy of $0.01 \mathrm{~mm}$.

The height and diameter of the pill type pieces (Figures 8 and 9) were measured, and the contraction after sintering was also determined.

Five pieces were measured after pressing and after sintering, randomly chosen from a 200-piece batch.

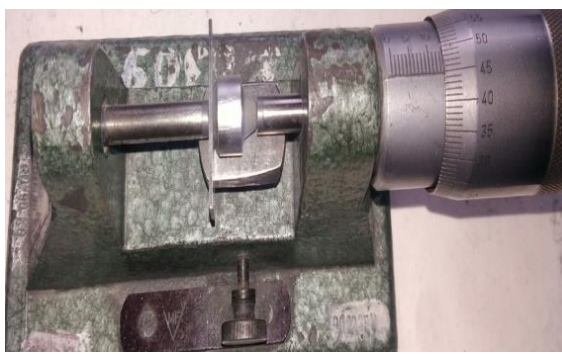

Figure 8: Measurement of the sintered piece with the micrometer

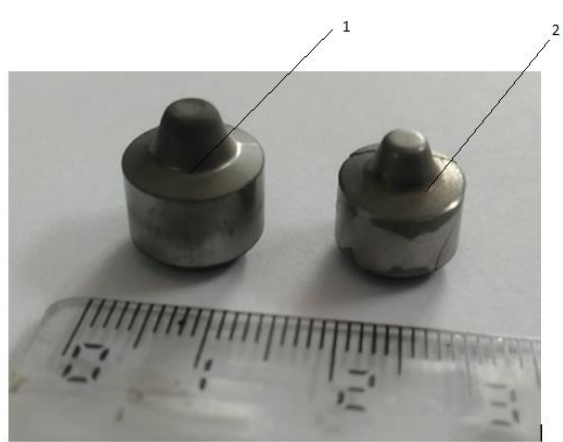

Figure 9: The pressed sample (1) next to the sintered piece (2)

The mass determination of the parts after sintering was performed by weighing using thermo balance, fig. 7
Following the measurements on five pressed and then sintered pieces, the shrinkages of Table 2 resulted.

Table 3

\begin{tabular}{|l|c|c|c|c|}
\hline \multirow{2}{*}{} & \multicolumn{3}{|c|}{ Mass, g } & \multirow{2}{*}{$\begin{array}{c}\text { Contraction } \\
\%\end{array}$} \\
\cline { 2 - 3 } & \multicolumn{2}{|c|}{ Condition } & Contraction & \\
\cline { 2 - 3 } & Pressed & Sintered & 1.009 & 0.889 \\
\hline $\begin{array}{l}\text { Tungsten pill } \\
\text { n } 1\end{array}$ & 12.151 & 12.043 & 1.009 & 0.889 \\
\hline $\begin{array}{l}\text { Tungsten pill } \\
\text { n 2 2 }\end{array}$ & 12.152 & 12.044 & 1.010 & 0.962 \\
\hline $\begin{array}{l}\text { Tungsten pill } \\
\text { n 3 } 3\end{array}$ & 12.156 & 12.039 & 1.010 & 0.971 \\
\hline $\begin{array}{l}\text { Tungsten pill } \\
\text { nr 4 }\end{array}$ & 12.156 & 12.038 & 1.009 & 0.921 \\
\hline $\begin{array}{l}\text { Tungsten pill } \\
\text { nr 5 }\end{array}$ & 12.157 & 12.045 & & \\
\hline
\end{tabular}

In order to determine the hardness of the sintered parts, the 251 VRSA AFFRI (Italy) is used in the advanced micro technology for the evaluation of the surface hardness of the manufactured parts of the industrial environment.

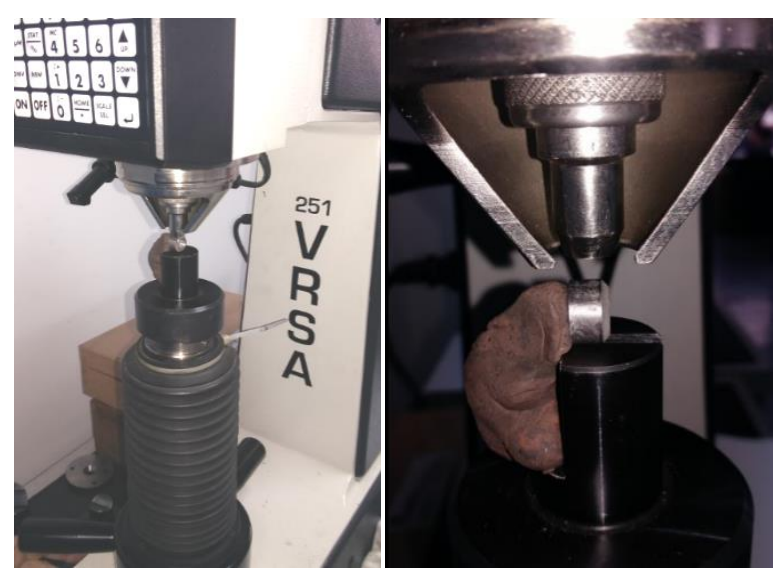

Figure 10: How to fix the sample to determine the hardness

Table 4 shows the results of the hardness test on the 5 pellet types

\begin{tabular}{|l|c|}
\hline Pellet & HRC Hardness \\
\hline Tungsten pellet no. 1 & 21,2 \\
\hline Tungsten pellet no. 2 & 22,0 \\
\hline Tungsten pellet no. 3 & 21,4 \\
\hline Tungsten pellet no. 4 & 22,1 \\
\hline Tungsten pellet no. 5 & 21,5 \\
\hline
\end{tabular}

In order to metallographic characterization of samples made by pressing and sintering using powder metallurgy, the longitudinal and transverse cutting of the pills will be performed. 


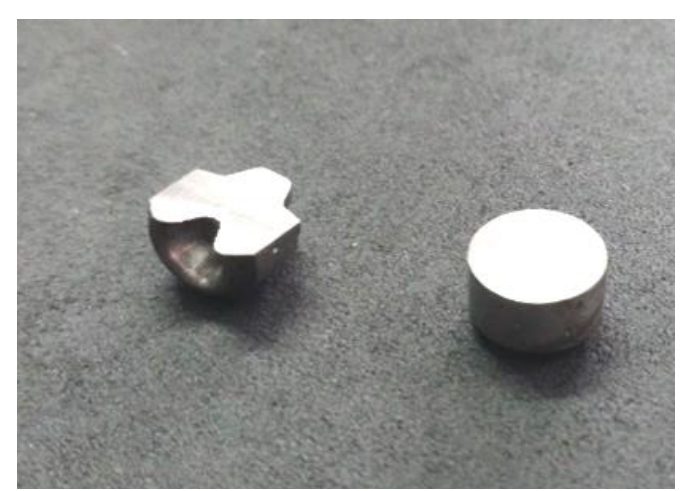

Figure 11: Longitudinal and transverse cuts

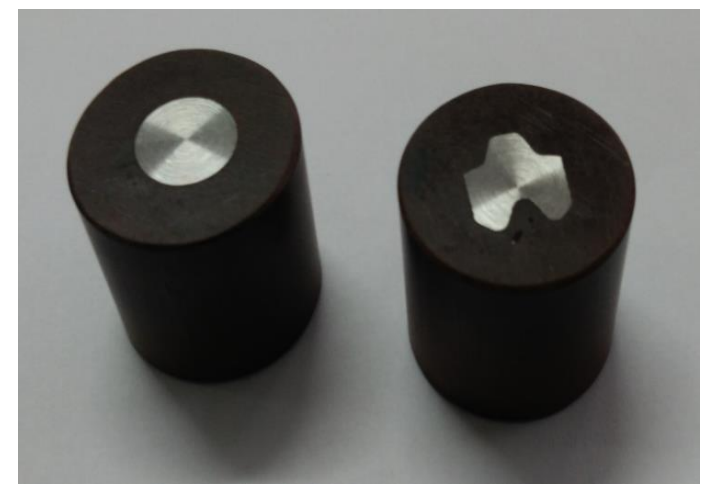

Figure 12: Samples embedded in the resin for the metallographic examination

The structural homogeneity obtained from the complex processing processes follows:

- homogenization of the metallic powder of $\mathrm{W}, \mathrm{Ni}, \mathrm{Fe}$, Mo (according to manufacturer's recipe)

- mixing homogenised metallic powder with polyethylene glycol (PEG) type binder

The sintered product with a fine structure also has a high hardness, while a rough coarse grain leads to a good toughness of the material.

The study with the naked eye or with a magnifying glass can reveal the existence of cracks, pits, pores, graphite inclusions and the presence of phase (in the gap).

The sample is ground according to known procedures and the polished surface is examined at a microscope, first at a magnification (x100) for porosity determination, and then, after chemical attack (Nital type), at a larger magnification (x10002000), to highlight the grain structure.

Prior to performing the metallographic attack, the porosity, at a relatively reduced magnification, $\mathrm{x} 100$, on unattended samples according to SR EN 24505-1996 was evaluated, by comparing the determined area of the slim with the representative series of the standard micrographs. The presence of free carbon will be highlighted, also on the unattended sample, by comparing the determined area of the sliver with the representative series of standard micrographs at an x 100 magnification. For the porosity evaluation, the Nikon ECLIPSE MA100 microscope (Figure 13)

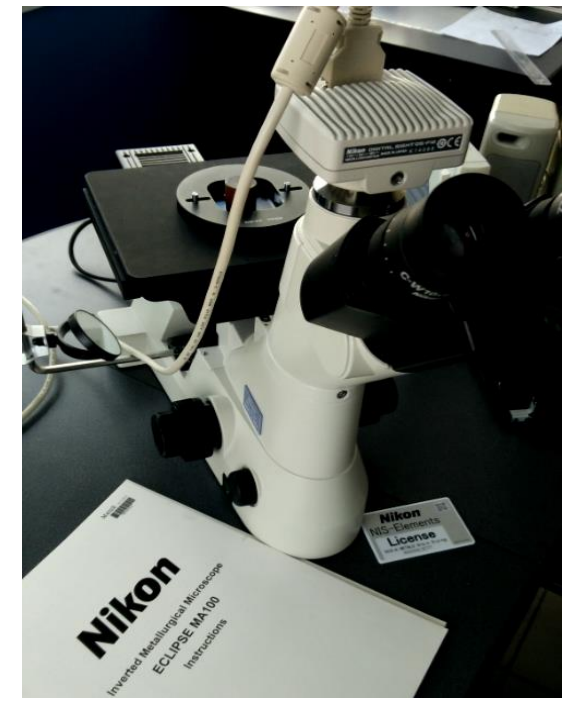

Figure 13: Nikon ECLIPSE MA100

In Figure 14 a, b show magnified x100 images for viewing the porosity of the bundle.

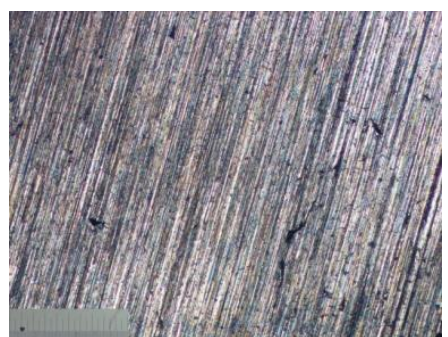

Figure 14 a: Porosity in the longitudinal section

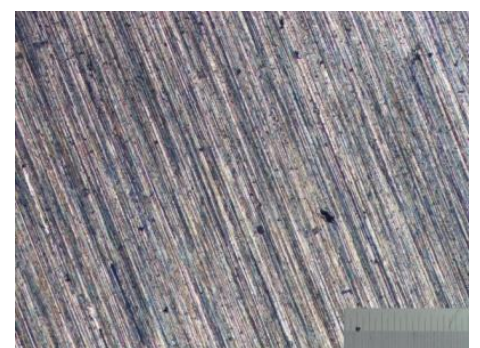

Figure 14 b: Cross-sectional porosity

a - Porosity is assessed by reporting the area occupied by pores in the target section and the total area. A graduated scale was superimposed over the target figure, the graduation value being $0.01 \mathrm{~mm}$, so the entire scale is $1 \mathrm{~mm}$. Areas representing the pores will be appreciated as geometric figures known as triangles, rectangles, circles, etc.

The total area of the target section is At $=2.1 \times 3.6$ $\mathrm{mm}=7.56 \mathrm{~mm}^{2}$.

Aria porilor Ap $=0,15 \mathrm{~mm}^{2}$

Porosity $\mathrm{P}=\frac{A p}{A t} 100=1,98 \%$

$\mathrm{b}$ - The total area of the target section is At $=2.08$ x $3.66 \mathrm{~mm}=7.61 \mathrm{~mm}^{2}$.

Pore area $A p=0,1 \mathrm{~mm} 2$

Porosity $\mathrm{P}=\frac{A p}{A t} 100=1,3 \%$ 
A porosity of less than or equal to $3 \%$ is considered to be a highly compacted sintered material with very good mechanical properties.

By evaluating the porosity, it results that a good quality material from a physical and mechanical point of view has been obtained.

The microstructure is examined according to SR EN 24499-1993, by phasing progressively, by chemical attack of the investigated surface with Nital reagent $2 \%$

Microscopy reveals the microstructure of the material by highlighting tungsten grains in a nickel and iron matrix.

The sintered pads were sectioned both transversally and longitudinally to highlight the degree of compaction of the powder mixture, porosity and various inclusions, taking into account that the products were developed by bilateral press, not isostatic.

In order to study the microstructure, the cut pieces were embedded in the resin and polished on the Alpha Beta Polisher Buehler (Figure 15), using grain 400, 600, 800, 1000, 1200 and 2500 grinding grains progressively. Polishing was done on a felt having a lubricant alumina suspension, $\mathrm{Al} 203$, with a grain size of $1 \mu \mathrm{m}$ and a $\mathrm{pH}$ of 7.0.

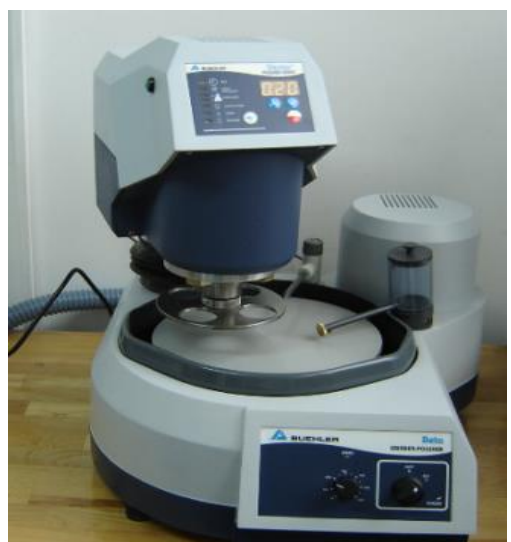

Figure: 15 The Buehler sander

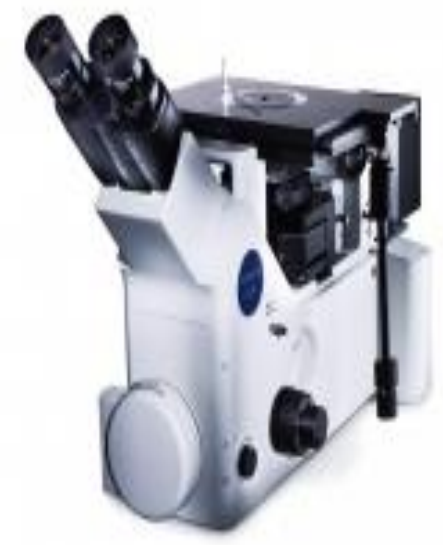

Figure:16 Olympus GX51 Microscope
The metallographic analysis was performed by optical microscopy according to SR EN 1321: 2000, STAS 7626-79, CR 12361: 1996 + AC: 1997, with the Olympus GX51 microscope (Figure 16) equipped with AnalySis imaging software.

Measuring conditions:

$\Rightarrow$ Temperature $+24^{\circ} \mathrm{C}$ (reference temperature +23 $\pm 5^{\circ} \mathrm{C}$ );

$\Rightarrow$ Humidity $45 \%$.

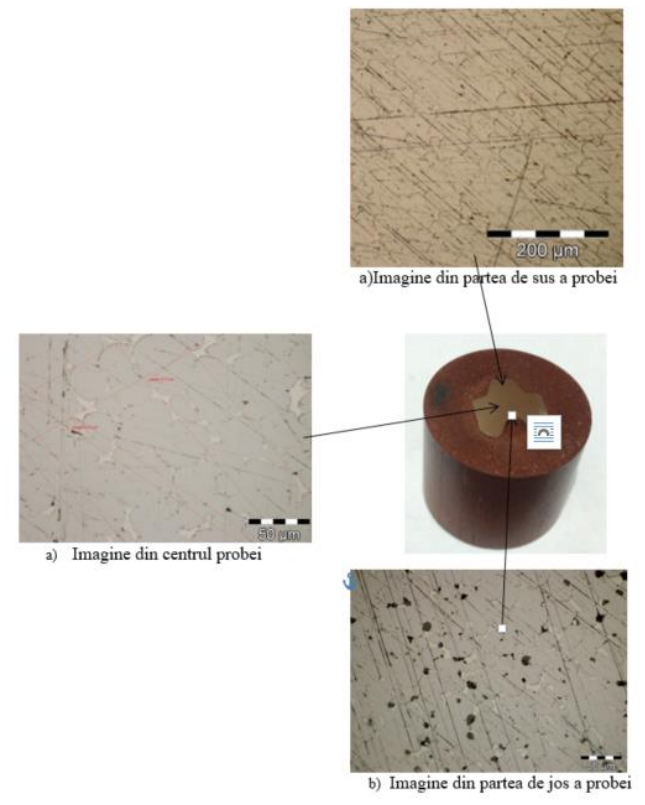

Figure 17: $a, b, c$-Microscopic images of the longitudinal section

It is noted that the sintered sample has a very good degree of compaction in the upper part and less good highlighted in the lower part, because the pressing was of the pseudo-bilateral type.

This type of pressing is the most used in powder metallurgy due to the possibility of producing a very large number of products in a relatively low time frame, of good quality, with acceptable costs. In order to achieve optimal compaction, it is necessary to make preset curves when lifting them, making it necessary to carry out laborious experimental determinations designed to determine with high precision the optimal pressing at which the compacted products present a uniform degree of compaction.

Taking into account the destination of the sintered parts, this is not an operationally negative aspect. The tungsten grain size is located between 10 $\mu \mathrm{m}$ and $45 \mu \mathrm{m}$ being embedded in $\mathrm{a} \mathrm{Ni}$ and $\mathrm{Fe}$ matrix.

In Figure $18 \mathrm{a}, \mathrm{b}$ is shown the microstructure in the transversely cut sample. It is noted the reduced existence of pores and inclusions.

In Figure 19 is a $1000 x$ optical microscopic image showing the dimensions of tungsten grains in a $\mathrm{Ni}$ matrix. 


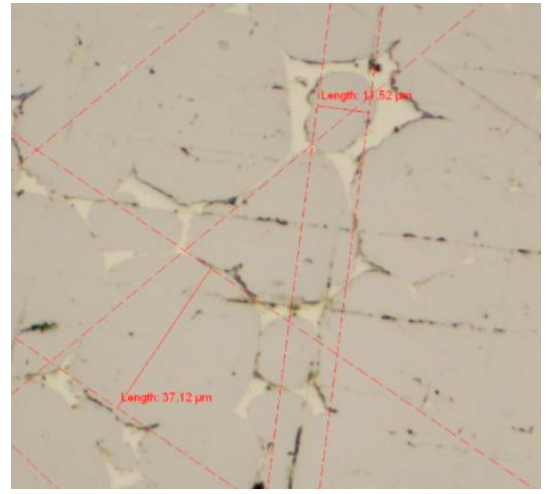

Figure 19: Optical microscopy image 1000x, cross section, sample center

By correlating the physical and mechanical parameters with the chemical and structural ones, we obtained a precise characterization of the products obtained by SC CARMESIN SA, which is in line with the final destination of the products requested by the customer.

\section{Conclusions}

The issues addressed relate to the production of sintered materials using powder metallurgy techniques / technologies and control systems.

These processes have been generated as a pressing necessity for obtaining a range of superior products in terms of physico-mechanical characteristics.

In defining these families of materials, it is necessary to carry out specific tests to investigate and control:

- the proportions of the main chemical components;

- the dimensional gradient of each component;

- the degree of bonding;

By identifying the main parameters, specific (well defined) mixtures / recipes can be made, with precise destinations in the activities to be used.

As the main priorities imposed by the pulverulent mixtures it is necessary to achieve a rigorous control of the mixtures and their main influence parameters. Increased precision in conducting their evaluation investigations contributes directly to increasing the quality of finished products made from sintered metal powders composite alloys.

The characteristics are determined for the $\mathrm{W}, \mathrm{Ni}$ and $\mathrm{Fe}$ powders as well as the sintered product, namely:

- apparent free-flowing density of the powder mixture for pressing;

- flow of pulverulent materials according to the determined mass in a given time unit (flow rate);

- the degree of wetting (humidity) of the powders as well as the powder mixture for pressing;

- density of sintered products;
- dimensional and mass determination of the parts after sintering;

- determining the hardness of the parts after sintering;

- Morphological and structural characterization of the parts after sintering.

A correct highlighting of apparent density and particle flow rate will allow for appropriate loading regimes for molds, an important process parameter for making high performance composites of metallic powdered products.

Industrial loading of the molds is done gravimetrically, a process directly influenced by the flow rate of the powders used.

These flow rates are influenced by the following factors:

- particle size (micron)

- the degree of lubrication (0.8 - $20 \%$ by mass), depending on the process used,

- the proportions of the components that make up the mixture,

- the particle form of the powder mixture particles.

The precise determination of the above mentioned parameters leads directly to the increase of the accuracy of the laboratory interpretations and implicitly, it is reflected in obtaining sintered products of similar quality to those produced within the EU, with lower cost prices.

As a result of the implementation of the project, the following results are estimated:

- Increase in turnover by at least $10 \%$

- Maintaining highly qualified jobs

- Creation of 1-2 new jobs in the perspective of the development of society

- Acquisition of new knowledge in the field

- Promotion and implementation of clean technologies (without cobalt)

- Increase the production blade by introducing new recipes of $\mathrm{W}$-sintered powder blends with $\mathrm{Fe}$ and $\mathrm{Ni}$ bonding elements.

\section{References}

[1] CALUGARU, G, APACHITEI, I, CALIMAN R. Pulberi metalice amorfe: materiale avansate. Editura Plumb, 1995, Bacau.

[2] GERMAN, R.M. Powder Metallurgy, Princeton, New Jersey, U.S.A., 1997

[3] NICA G., Producerea şi utilizarea pulberilor, Îndrumar de laborator, 1998, Universitatea "Politehnica" Timişoara

[4] COJOCARU, Mihai. Producerea și procesarea pulberilor metalice. Editura Matrix Rom, 1998, Bucuresti

[5] SIMITI, Z. V. Proprietati tehnologice în metalurgia pulberilor, Ed. Enciclopedică, 2000, Bucuresti

[6] MUREŞAN, R. Metalurgia pulberilor, U.T. Press, Cluj-Napoca, 2005 